\title{
ESTADO DA ARTE DO PROCESSO PRODUTIVO DA CAL NA REGIÃO CENTRO OESTE DE MINAS GERAIS
}

\author{
Ricardo Carrasco Carpio ${ }^{1}$ \\ Carlos Antônio Rufino Júnior ${ }^{2}$ \\ Leandro de Souza Lemos ${ }^{3}$ \\ Vanessa dos Santos Sousa ${ }^{4}$ \\ Vinicius Augusto Dantas 5
}

\begin{abstract}
RESUMO
As indústrias de cal são caracterizadas pelas altas emissões de dióxido de carbono $\left(\mathrm{CO}_{2}\right)$ na atmosfera. Isto se deve ao fato das indústrias atuarem com tecnologias ultrapassadas, resultando em alto consumo de combustível, baixa eficiências energéticas e grandes impactos ambientais. Para diminuir os danos ambientais causados pela indústria de cal é necessário o conhecimento do processo produtivo, das tecnologias empregadas e dos impactos ambientais. Por essa razão, este trabalho tem por objetivo fazer uma análise do processo produtivo da cal, desde as jazidas até o produto final, mostrando as tecnologias empregadas em cada etapa do processo.
\end{abstract}

Palavras-chave: Indústrias de cal. Processo produtivo. Impacto ambiental.

\section{STATE-OF-THE-ART ON THE MANUFACTURING PROCESS OF LIME IN MID WEST REGION OF MINAS GERAIS}

\begin{abstract}
The lime industries are characterized by high emissions of $\mathrm{CO}_{2}$ in the atmosphere. This is because the industries are using outdated technology, resulting in high fuel consumption, low energy efficiencies and high environmental impacts. To reduce the environmental damages caused by the lime industry, it is necessary to know the manufacturing process, the technologies used and the environmental impacts. Therefore this paper aims to analyze the manufacturing process of lime, from the limestone quarries to the final product, showing the technologies used in each step of the process.

\footnotetext{
${ }^{1}$ Doutorado em Engenharia Mecânica pela Universidade Federal de Itajubá (Unifei). Secretário de Extensão, Pesquisa e Pós-graduação e professor do Instituto Federal de Minas Gerais (IFMG) Campus Formiga. E-mail: ricardo.carrasco@ifmg.edu.br

${ }^{2}$ Graduando em Engenharia Elétrica pelo Instituto Federal de Minas Gerais (IFMG) Campus Formiga. E-mail: junin.udia@hotmail.com

${ }^{3}$ Graduando em Engenharia Elétrica pelo Instituto Federal de Minas Gerais (IFMG) Campus Formiga. E-mail: geomanc3r@hotmail.com

${ }^{4}$ Graduando em Engenharia Elétrica pelo Instituto Federal de Minas Gerais (IFMG) Campus Formiga. E-mail: vanessaksd@yahoo.com.br

${ }^{5}$ Graduando em Engenharia Elétrica pelo Instituto Federal de Minas Gerais (IFMG) Campus Formiga. E-mail: viniciusaugusto.dantas@yahoo.com.br
} 
Keywords: Lime Industries. Manufacturing process. Environmental impact.

\section{INTRODUÇÃO}

A cal é um dos produtos mais antigos produzidos pelo homem. Ela é utilizada em várias áreas, como por exemplo, na indústria metalúrgica, de construção e química (BOYNTON, 1988; OATES, 1998; OCHOA, 2000 apud OCHOA et al., 2010). Existem registros do uso deste produto que datam há mais de 2000 anos. Um exemplo é a muralha da China, onde se pode encontrar, em alguns trechos da obra, uma mistura bem compactada de terra argilosa e cal (ABPC, 2007 apud BAJAY; SANT'ANA, 2010).

As pequenas empresas dos países em desenvolvimento ainda operam com tecnologias ultrapassadas, uma vez que os esforços para reduzir os custos e o impacto ambiental da produção de cal normalmente envolvem a introdução de sofisticados instrumentos e equipamentos, e também, implicam no uso de controle automático de diversos parâmetros de operação, sendo que essas empresas não possuem recursos suficientes (SILVA, 2009; OCHOA et al., 2010). Uma forma de reduzir os impactos ambientais e os custos de produção, melhorando a qualidade do produto final, sem grandes investimentos, é por meio do controle de processo (OCHOA et al., 2010).

O impacto ambiental da produção de cal pode ser de escala local, regional ou global. Dentre os efeitos locais podemos citar as emissões de material particulado e as mudanças na paisagem por causa da mineração de calcário. A emissão de dióxido de enxofre $\left(\mathrm{SO}_{2}\right)$ e óxido de nitrogênio $\left(\mathrm{NO}_{\mathrm{x}}\right)$ contribui para a chuva ácida (GUTIÉRREZ et al., 2012). O processo produtivo da cal implica na emissão de grandes quantidades de dióxido de carbono $\left(\mathrm{CO}_{2}\right)$, ator principal nas mudanças climáticas, tendo em vista que a produção de 1 tonelada de cal implica na emissão de 1,2 toneladas de $\mathrm{CO}_{2}$ (OCHOA et al., 2010; COMISSÃO EUROPÉIA, 2001 apud GUTIÉRREZ et al., 2012).

O objetivo deste artigo é fazer um estudo sobre o processo produtivo da cal. Identificar as tecnologias aplicadas nas indústrias de cal e os parâmetros operacionais dos fornos da região centro-oeste de Minas Gerais.

Este artigo foi dividido em três tópicos com o objetivo de apresentar didaticamente o processo produtivo da cal. O primeiro tópico corresponde à introdução, na qual se delimita o problema e define os seus objetivos. O segundo tópico tem por objetivo discorrer a respeito de como a cal é produzida, os aspectos químicos, energéticos e ambientais. Já o terceiro, visa a expor as conclusões alcançadas com o desenvolvimento deste trabalho. 


\section{O CICLO PRODUTIVO DA CAL}

\subsection{Produção de cal viva e cal hidratada}

Para produzir a cal, é necessário converter o carbonato de cálcio $\left(\mathrm{CaCO}_{3}\right)$, comumente chamado de calcário, em óxido de cálcio $(\mathrm{CaO})$, normalmente chamado de cal ou de cal viva.

A equação química aproximada para este processo é:

$$
\mathrm{CaCO}_{3}+\text { Calor } \leftrightarrow 56 \mathrm{CaO}+44 \mathrm{CO}_{2}
$$

A substância $\mathrm{CaO}$ é muito reativa e quando hidratada (adicionado $\mathrm{H}_{2} \mathrm{O}$ ), forma a cal hidratada, também chamada de cal apagada, a qual é empregada como aglomerante na construção civil, ou seja, forma uma espécie de cola que dá liga a elementos como pedra, areia e cimento. Durante a hidratação da cal, há grande liberação de calor (HILL, 1997).

Este processo de conversão é realizado em alto-fornos, os quais, normalmente, são fornos do tipo vertical, devido a sua alta eficiência, comparados aos outros tipos de fornos (BES, 2006). Para que esta conversão seja realizada, eleva-se a temperatura do calcário (no intervalo de $900^{\circ} \mathrm{C}$ a $\left.1200^{\circ} \mathrm{C}\right)$, para liberar o dióxido de carbono $\left(\mathrm{CO}_{2}\right)$ contido no carbonato de cálcio $\left(\mathrm{CaCO}_{3}\right)(\mathrm{HILL}, 1997)$.

Continuando a aproximação para a hidratação, tem - se:

$$
56 \mathrm{CaO}+18 \mathrm{H}_{2} \mathrm{O} \leftrightarrow 74 \mathrm{Ca}(\mathrm{OH})_{2}+\text { Calor }
$$

\subsection{Etapas do processo produtivo da cal}

A produção de cal pode ser resumida em cinco etapas básicas conforme Gutiérrez et al. (2012):

1. Exração de calcário;

2. Britagem de calcário e peneiramento;

3. Calcinação de calcário;

4. A hidratação da cal e de classificação de cal hidratada;

5. Acondicionamento.

A extração da rocha calcária é a primeira etapa da produção de cal. Utiliza-se explosivos e equipamentos especiais como as perfuratrizes, para fazer a perfuração e 
desmonte de rochas da mina. Após isto carregadeiras e caminhões de alta capacidade são empregadas para transportar o calcário da mina até o britador. Ocorrendo a seguir o beneficiamento através de britagem (VOTORANTIM, 2013).

A segunda etapa é o processo de britagem do calcário. A britagem é o processo de fragmentação da pedra calcária. Esta etapa tem por objetivo retirar as impurezas do processo e classificar o calcário por diferentes especificações granulométricas, até a obtenção de bitola do calcário apropriada ao processo de calcinação. Os finos que não são utilizados no processo de calcinação são destinados à venda como agregados e também para a produção de calcário agrícola. Este processo pode ser dividido em várias etapas de britagem e estas etapas são diferenciadas pela sua capacidade de redução das rochas para a classificação em peneiras dimensionadas para cada produto fim. As pilhas tipo trincheiras alimentam as transportadoras correias que são responsáveis por fazer o transporte do material do britador até os fornos (VOTORANTIM, 2013).

O processo de calcinação do calcário classificado visa à decomposição do carbonato de cálcio, $\mathrm{CaCO}_{3}$, em óxido de cálcio, $\mathrm{CaO}$, através da queima do combustível, que aquece o calcário com temperatura no intervalo de $900{ }^{\circ} \mathrm{C}$ a $1.350{ }^{\circ} \mathrm{C}$. As reações químicas e físicas transformam o calcário em cal virgem. Depois de concluída esta etapa, o produto ainda na sua forma bruta e "virgem" segue para seu ponto de estocagem para beneficiamento (redução granulométrica) (VOTORANTIM, 2013).

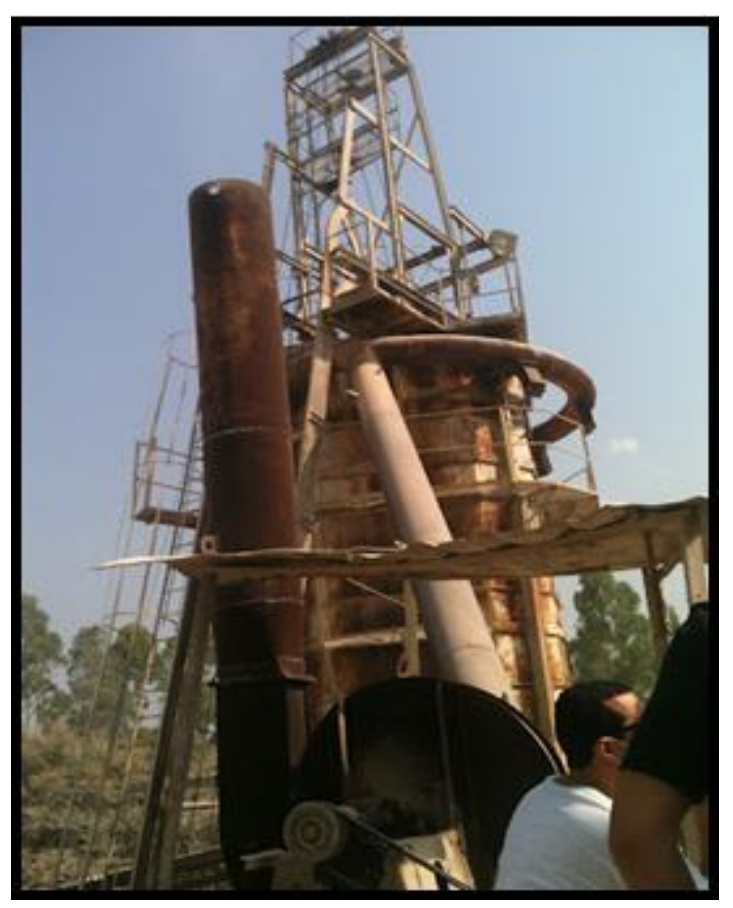

Figura 1 - Forno de cal da indústria CalMax localizada na região Centro Oeste de Minas Gerais. Fonte: Indústria CalMax

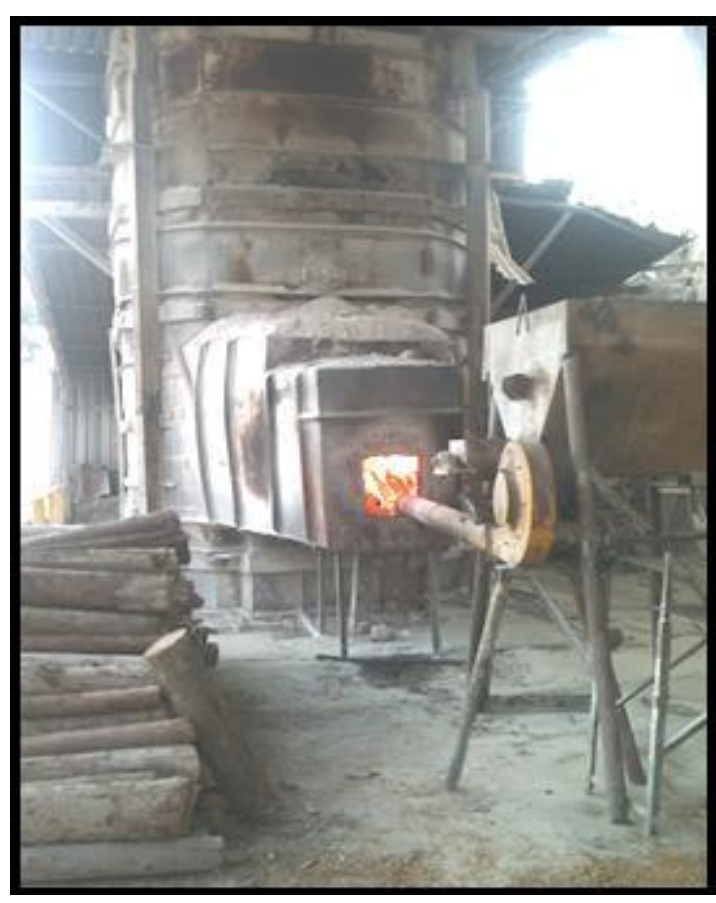

Figura 2 - Forno de cal da indústria CalMax localizada na região Centro Oeste de Minas Gerais. Fonte: Indústria CalMax 
A hidratação ocorre com a adição de água á cal virgem. Para que o produto não provoque nenhum tipo de reação ao usuário final, ele deve seguir especificações controladas e estar de acordo com a norma NBR-7175 que normaliza a cal hidratada para argamassas. Deve também respeitar o tempo de cura para hidratação completa e as normas para a classificação da cal (VOTORANTIM, 2013).

As normas da Associação Brasileira de Normas Técnicas (ABNT) devem ser seguidas para garantia da qualidade do produto cal, com especificações destinadas à construção civil (VOTORANTIM, 2013).

As etapas de embalagem e expedição ao mercado consumidor são as últimas etapas do processo de produção da cal. Para fazer a embalagem do produto, normalmente utilizam equipamentos rotativos de ensaque em embalagens de $20 \mathrm{Kg}$ (Cal Hidratada $\mathrm{CH}$ III) e $8 \mathrm{Kg}$ (Cal de Pintura), tendo como principal finalidade o controle da quantidade estipulada para cada embalagem de produto. Após a cal ter sido ensacada ela segue para paletização e é expedida ao mercado consumidor (VOTORANTIM, 2013).

Em cada etapa pode-se determinar as entradas e as saídas do processo, conforme o fluxograma da figura 1 :

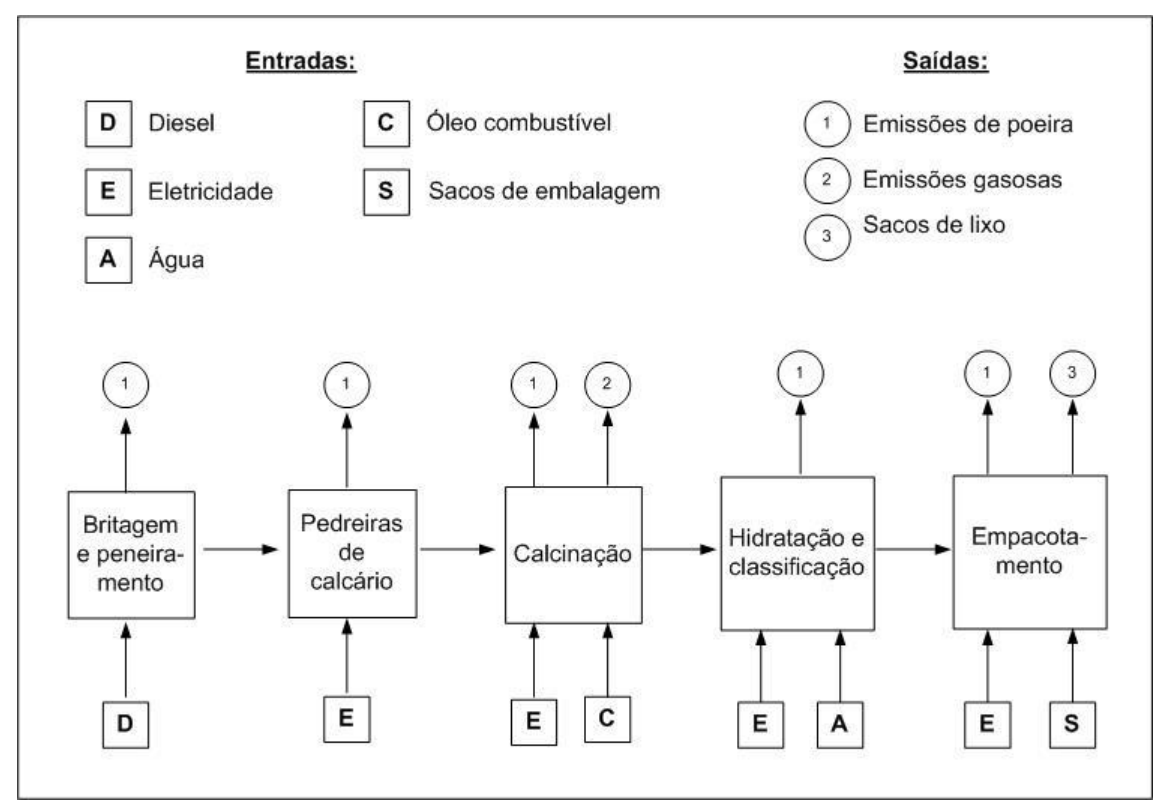

Figura1 - Fluxograma do processo de produção de cal. Fonte: Gutierrez et al. (2012). 


\subsection{Tipos de calcário}

Existem vários tipos de calcário. Devido ao amplo uso nas indústrias em geral e à disponibilidade no mercado, serão abordados somente dois tipos: o calcário calcítico e o calcário dolomítico. $\mathrm{O}$ calcário calcítico contém somente $\mathrm{CaCO}_{3}$. Por outro lado, o calcário dolomítico têm a fórmula química $\mathrm{CaCO}_{3} \bullet \mathrm{MgCO}_{3}$, ou seja, é uma "mistura" de carbonatos de cálcio e magnésio, na proporção de 1:1 de suas moléculas (HILL, 1997).

\subsection{Tipos de cal}

A cal pode ser classificada, conforme o óxido predominante, em:

Cal virgem Cálcica - com óxido de cálcio entre $100 \%$ e $90 \%$ do óxido total presente.

Cal virgem Magnesiana - com teores intermediários de óxido de cálcio, entre 90\% e $65 \%$ do óxido total presente.

Cal virgem Dolomítica - com óxido de cálcio entre $65 \%$ e $58 \%$ do óxido total presente (SILVA, 2009).

\subsection{Consumo de água na hidratação da cal}

Adicionando água $\left(\mathrm{H}_{2} \mathrm{O}\right)$ ao óxido de cálcio $(\mathrm{CaO})$, gera-se a cal hidratada, como expresso na equação 2. Para determinar a quantidade de água necessária à hidratação da cal viva, é necessário relacionar o peso molar da água $\left(\mathrm{H}_{2} \mathrm{O}\right)$ e da cal $(\mathrm{CaO})$, como abaixo:

$$
\begin{aligned}
& \mathrm{CaO}=56 \mathrm{~g} . \\
& \mathrm{H}_{2} \mathrm{O}=18 \mathrm{~g} . \\
& \mathrm{Ca}(\mathrm{OH})_{2}=74 \mathrm{~g} .
\end{aligned}
$$

Assim podemos realizar a seguinte relação:

$$
\begin{aligned}
18 \mathrm{H}_{2} \mathrm{O} & \rightarrow 74 \mathrm{Ca}(\mathrm{OH})_{2} \\
\mathrm{X} & \rightarrow 1 \\
X & =\frac{18}{74}=0,24 \mathrm{~L}
\end{aligned}
$$


A partir disso, determina- se que para produzir uma tonelada de cal hidratada são necessários 240 litros de água.

\subsection{Tipos de fornos}

Os fornos de calcinação se caracterizam em razão da matéria prima utilizada, quantidade produzida e tipo de combustível empregado, conforme Silva (2009, p. 27-28):

- Forno de barranco descontínuo: forno de alvenaria, com revestimento de tijolos comuns recozidos ou mesmo sem revestimento. Geralmente encravado na meia encosta de pequenas elevações, descontínuo, com carga e descarga manuais, produção até 1.000 toneladas/ano, fornalha geralmente constituída por abóbada própria. Não há zonas de aquecimento e précalcinação (substituídas por uma fase de "esquente"). O consumo de combustível é muito alto (em média, de $280 \mathrm{Kg}$ de óleo combustível BPF ou 2,6 metros cúbicos de lenha ou mais, por tonelada de cal virgem), possuindo tiragem natural.

- Forno de barranco contínuo: forno de alvenaria, bem construído, alto, com chaminé, "boca de fogo" e "cinzeiro", cilíndrico, com revestimento de tijolos recozidos e refratários. Geralmente encravado na meia encosta e sustentado por estruturas de alvenaria ou metálicas, com carga e descarga semi-automáticas, produção de 3000 toneladas/ano (em média), sem recuperação de calor (dos gases e da cal virgem), alto consumo de combustível (em média $220 \mathrm{~kg}$ de óleo combustível BPF ou 1,7 metro cúbico de lenha por tonelada de cal virgem), possuindo tiragem forçada.

- Forno vertical metálico de cuba simples: forno metálico, contínuo, geralmente do tipo AZBE, com tiragem forçada e controle termodinâmico, cilíndrico, revestimento refratário e isolante, carga e descargas automáticas, recuperação parcial do calor perdido nos gases e na cal virgem, produção de até 350 toneladas/dia de cal, consumo de combustível em média de 132 $\mathrm{kg}$ de óleo combustível BTE ou 1,1 metro cúbico de lenha por tonelada de cal virgem.

- Forno vertical metálico de cubas múltiplas e fluxos paralelos: forno metálico, contínuo, geralmente do tipo MAERZ, com tiragem forçada e controle termodinâmico, secção circular ou retangular, revestimento interno refratário e isolante, carga e descargas automáticas. Neste tipo de forno, os fluxos dos gases e do ar de combustão são invertidos alternadamente nas cubas (em cada 12 minutos, nos de duas cubas) e uma delas passa a funcionar como recuperadora de calor, com produção de até 144.000 toneladas de cal ano, consumo de combustível em média $89 \mathrm{~kg}$ de óleo combustível BPF e BTE, por tonelada de cal virgem.

Os altos-fornos podem ser divididos didaticamente em três zonas para uma melhor compreensão: zona de pré-aquecimento, zona de calcinação e zona de resfriamento, conforme exposto na Figura 2. O calcário entra e passa pela zona de pré-aquecimento, onde ele começa a ser aquecido para ser calcinado na zona de calcinação. A zona de calcinação possui temperatura entre $900^{\circ} \mathrm{C}$ e $1200^{\circ} \mathrm{C}$. Após ser calcinado, o calcário é resfriado na zona de resfriamento. 
A fase de calcinação é responsável por $50 \%$ dos custos de produção (OCHOA et al., 2010).

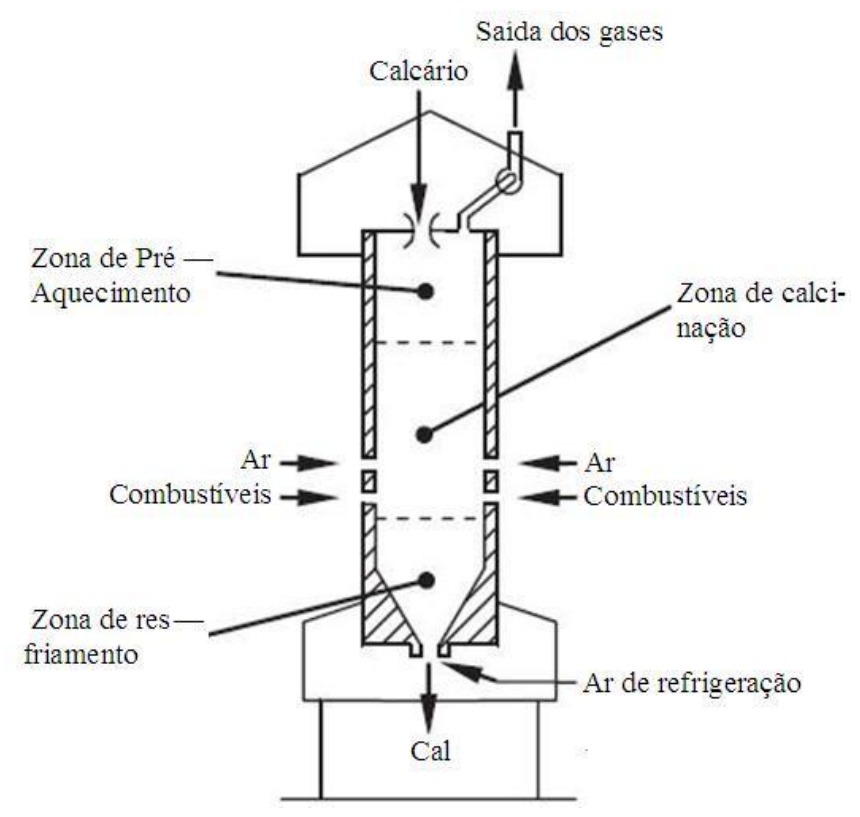

Figura 2 - Forno vertical de cal. Fonte: Ochoa et al. (2010).

\subsection{Poder calorífico dos combustíveis na indústria de cal}

O poder calorífico é definido como sendo a "quantidade de calor que se desprende durante a combustão completa da unidade de massa do combustível, podendo ser medida em kJ/kg”. O teor de umidade influencia no poder calorífico (CORTEZ; LORA, 1997).

Segundo Cortez e Lora (1997, p. 24), “a diferença entre o poder calorífico superior (PCS) e o poder calorífico inferior (PCI) é a energia requerida para evaporar a umidade presente no combustível e a energia de oxidação do hidrogênio presente no mesmo".

Nas indústrias o calor latente pode ser desprezado, devido à temperatura dos gases de saída geralmente ser maior que a temperatura de condensação. Por isso o PCI é mais utilizado na prática (CORTEZ; LORA, 1997).

A Tabela 1 mostra o poder calorífico superior de alguns tipos de combustíveis utilizados para queima em fornos. 
Tabela 1 - Poder calorífico da biomassa em base seca

\begin{tabular}{l|c}
\hline \multicolumn{1}{c|}{ Tipo de Biomassa } & $\begin{array}{c}\text { Poder Calorífico Superior (PCS) } \\
\text { (MJ/kg) }\end{array}$ \\
\hline Pinus & 20,02 \\
\hline Eucalipto & 19,42 \\
\hline Casca de Arroz & 16,14 \\
\hline Bagaço de Cana & 17,33 \\
\hline Casca de Coco & 19,04 \\
\hline Sabugo de Milho & 18,77 \\
\hline Ramas de Algodão & 18,26 \\
\hline Resíduos Sólidos Urbanos & 19,87 \\
\hline Excrementos de Gado & 17,36 \\
\hline Fonte: Cortez e Lora (1997)
\end{tabular}

\subsection{Teor de umidade da madeira}

Devido ao amplo uso de madeira como combustível na região centro-oeste de Minas Gerais, é de grande importância conhecer o teor de umidade deste combustível. O teor de umidade é a porcentagem de água em relação a uma determinada massa de madeira. Quando o teor de umidade é baixo, reduz-se assim o custo de transporte e agrega valor ao combustível (QUIRINO et al., 2005).

O volume de umidade máximo que uma madeira pode ser queimada no forno está em torno de $65 \%$ a $70 \%$ em base úmida. Essa umidade faz com que ocorra uma perda de calor nos gases de combustão em forma de vapor de água, já que a umidade da madeira evapora e absorve energia em combustão. Quando a madeira possui muita umidade, há perda de calor, e é importante que se forneça calorias de origem externa para secar a madeira antes da combustão (QUIRINO et al., 2005).

Quanto maior o conteúdo de umidade da madeira, menor é o seu poder de combustão, devido ao processo de evaporação da umidade, o qual absorve energia em combustão (CUNHA et al., 1989 apud QUIRINO et al., 2005). 


\subsection{Constituição química da madeira}

Conhecer a composição elementar do combustível é de extrema importância, tendo em vista que a mesma é levada em consideração para o cálculo do PCI e do PCS. A variação na composição química, dimensões, forma e arranjo dos elementos anatômicos influencia nas características energéticas de várias madeiras (QUIRINO et al., 2005).

A Tabela 2 apresenta alguns resultados de uma análise imediata e elementar de alguns tipos de biomassa.

Tabela 2 - Composição elementar da biomassa (em base seca)

\begin{tabular}{l|c|c|c|c|c|c}
\hline \multirow{2}{*}{ Tipo de Biomassa } & \multicolumn{5}{|c}{ Composição Elementar (\%) } \\
\cline { 2 - 7 } & C & H & O & N & S & A \\
\hline Pinus & 49,25 & 5,99 & 44,36 & 0,06 & 0,03 & 0,3 \\
\hline Eucalipto & 49,00 & 5,87 & 43,97 & 0,30 & 0,01 & 0,72 \\
\hline Casca de Arroz & 40,96 & 4,30 & 35,86 & 0,40 & 0,02 & 18,34 \\
\hline Bagaço de Cana & 44,80 & 5,35 & 39,55 & 0,38 & 0,01 & 9,79 \\
\hline Casca de Coco & 48,23 & 5,23 & 33,19 & 2,98 & 0,12 & 10,25 \\
\hline Sabugo de Milho & 46,58 & 5,87 & 45,46 & 0,47 & 0,01 & 1,40 \\
\hline Ramas de Algodão & 47,05 & 5,35 & 40,77 & 0,65 & 0,21 & 5,89 \\
\hline
\end{tabular}

Fonte: Cortez e Lora (2005).

\section{CONCLUSÃO}

A tecnologia utilizada nas indústrias de cal influencia diretamente nos impactos ambientais causados pela produção da cal. Assim, são necessários estudos avaliativos sobre a melhor tecnologia a ser empregada, conhecimento sobre o melhor forno, combustível e matéria prima a serem empregados na produção da cal.

As pequenas empresas dos países em desenvolvimento ainda operam com baixas tecnologias, uma vez que os esforços para reduzir os custos e os impactos ambientais da produção de cal, normalmente, envolvem a introdução de instrumentos e equipamentos sofisticados, sendo que essas empresas não possuem recursos suficientes. No entanto, a redução dos impactos ambientais causados e dos custos de produção pode ser obtida 
melhorando a qualidade do produto final, sem grandes investimentos, por meio do controle de processo.

Existem vários tipos de fornos de cal. Cada tipo de forno é empregado conforme a matéria prima e combustível utilizado, bem como quanto à quantidade de cal a ser produzida. Os fornos verticais podem ser divididos em três partes: zona de pré-aquecimento, zona de calcinação e zona de resfriamento, sendo a zona de calcinação responsável por $50 \%$ dos custos de produção.

Podem ser utilizados diversos tipos de combustíveis para a queima, a fim de gerar calor para calcinar o calcário. Contudo, é necessário observar o teor de umidade presente no respectivo combustível, evitando combustíveis com alto teor de umidade. Cada combustível tem suas próprias características químicas, o que influencia diretamente no seu poder calorífico, sendo este fator determinante. Não podemos olvidar que a disponibilidade e o custo do combustível também devem ser levados em consideração para escolha do combustível a ser utilizado.

\section{REFERÊNCIAS}

ASSOCIAÇÃO BRASILEIRA DOS PRODUTORES DE CAL (ABPC). Disponível em: <http://www.abpc.org.br/>. Acesso em: 15 set. 2013.

BAJAY, S. V.; SANT'ANA, P. H. de M. Oportunidades de eficiência energética para a indústria: relatório setorial cal e gesso. Brasília: CNI, 2010.

BES, A. Dynamic process simulation of limestone calcinations in normal shaft kilns. Doctoral Thesis, Otto-von-Guericke University, Magdeburg, 2006. Disponível em: <www.uni-magdeburg.de/isut/TV/English/Research/Project/Bes.pdf >. Acesso em: 03 set. 2013.

BOYNTON, R. S. S. Chemistry and tecnology of lime and limestone. New York: John Wiley \& Sons Inc., 1988. p. 532.

BRIANE, D.; DOAT, J. Guide technique de la carbonization: la fabrication du charbon de bois. Aix-em-Provence: Édisud, 1985. p.180-1985.

BRITO, J. O.; BARRICHELO, L. E. G. Comportamento de madeiras nativas do maranhão frente ao processo de destilação seca. Brasil florestal, DF, ano 11, n. 45, p. 47-55, jan/fev/mar. 1981. 
CASTILLO, M. E. U. Determinacion del poder calorífico de 20 espécies florestales de la amazonia peruana. Revista Florestal do Peru, v. 12, n. 1-2, p. 98-117, 1994.

CORTEZ, L. A. B.; LORA, E. S. Tecnologias de conversão da biomassa. Manaus: EDUA/EFEI, 1997. (Sistemas Energéticos II).

CUNHA, M. P. S. C. et al. Estudo químico de 55 espécies lenhosas para geração de energia em caldeiras. In: ENCONTRO BRASILEIRO EM MADEIRAS E EM ESTRUTURAS DE MADEIRA, 3., 1989, São Carlos. Anais... São Carlos: [s.n.], 1989. v. 2, p. 93-121.

GUTIÉRREZ, A. S. et al. Evaluation of the environmental performance of lime production in Cuba. Journal of Cleaner Production, v. 31, p. 126-136, aug. 2012.

HILL, N.; MASON, K. How to calculate the energy efficiency of your lime burning process. Practical Action, World Cement, 1997.

JARA, E. R. P. O poder calorífico de algumas madeiras que ocorrem no Brasil. São Paulo: Instituto de Pesquisas Tecnológicas (IPT), 1989. (Comunicação Técnica, 1797).

OATES, J. A. Lime and limestone: chemistry and tecnology and uses. Weinheim: WileyVCH, 1998.

OCHOA, P. A. G. et al. Cleaner production in a small lime factory by means of process control. Journal of Cleaner Production, v. 18, n. 12, p. 1171-1176, apr. 2010.

OCHOA, P. A. G. 2000. Doctoral Thesis. Cuba: University of Cienfuegos, 2000

QUIRINO, W. F. et al. Poder calorífico da madeira e de materiais lignocelulósicos. Revista da Madeira, n. 89, p. 100-106, apr. 2005.

SILVA, J. O. Perfil da Cal. [S.1.]: Ministério de Minas e Energia (MME), 2009.

VOTORANTIM. Processo de fabricação da cal. 2013. Disponível em:

< http://www.vcimentos.com.br/htms-ptb/Produtos/Cal_procFabricacao.html >. Acesso em: 22 out. 2013.

Recebido em: 15/09/2013

Aprovado em: 17/10/2013 